\title{
Dom e troca no vocabulário indo-europeu: comentário sobre um texto de Benveniste
}

Silvana Silva*

\begin{abstract}
Só um ser que fala, quer dizer, pensa, pode ter mão e executar em seu manejo obras da mão (Heidegger). A mão do homem é pensada desde o pensar, mas esse é pensado a partir da palavra e da língua. [...] a mão do homem dá e se dá, enquanto o homem como simples animal, inclusive racional, pode somente tomar, isto é, fazer uso das coisas. Nada é menos seguro do que a distinção entre dar e tomar nas línguas que falamos (remeto aqui ao célebre texto Dom e troca no vocabulário indo-europeu, de Émile Benveniste) e na experiência de uma economia - simbólica ou imaginária, consciente ou inconsciente, todos os valores que esperam ser reelaborados desde a precariedade dessa oposição de dom e da apreensão, do dom que constitui um presente e daquele que toma, guarda ou retira, do dom que faz e do dom que faz mal, do presente e do veneno (DERRIDA, 2016, p. 511-3).
\end{abstract}

\section{Resumo}

O presente artigo pretende fazer um comentário do texto "Dom e troca no vocabulário indo-europeu" procurando observar suas relações com textos da seção "O homem na língua", dos volumes de Problemas de Linguística Geral, e também com discussões presentes no livro Economia, de Vocabulário das instituições indo-européias. Tal comentário abrange quatro tarefas: 1. propor uma conceituação teórica; 2. problematizar noções anteriores (pressupostos); 3. propor uma reelaboração da rede conceitual do autor; 4. levantar hipóteses para uma prospecção teórica.

Palavras-chave: Émile Benveniste. Dom e troca. Reciprocidade. Teoria da enunciação.

\section{Antecedentes da questão: língua, indivíduo e sociedade}

Como articular as noções de língua, indivíduo e sociedade? Apesar de um certo exagero na definição do texto "Dom e troca no vocabulário indo-europeu" Derrida (2016) chama-o de 'célebre' -, sua citação nos toca por articular uma discussão geral suscitada pelo texto - o

\footnotetext{
Professora do Curso de Letras e do Programa de Pós-Graduação em Letras da Universidade Federal do Rio Grande do Sul (Ufrgs). E-mail: ssilvana2011@gmail.com
}

Data de submissão: set. 2018 - Data de aceite: out. 2018 http://dx.doi.org/10.5335/rdes.v14i3.8533 
gesto, o fazer do homem - e uma questão particular - o vocabulário das línguas. Ter encontrado esse texto nos faz acreditar que é possível apostar numa leitura linguística de um texto não tão célebre assim para os linguistas.

Ainda, segundo Flores (2013), a articulação entre língua, indivíduo e sociedade constitui um tema um tanto polêmico na obra de Benveniste, em parte por sua suposta relação com o marxismo. De sua reflexão, nos interessa reter uma afirmação:

Benveniste não opõe indivíduo e sociedade. Pelo contrário, é na dialética que os engloba que se pode achar o fundamento linguística da subjetividade. Sugiro, ainda, para abordar o assunto com mais profundidade associá-lo à sexta parte dos Problemas de Linguística Geral, Léxico e Cultura. O começo certamente deveria se dar com o texto Dom e troca no Vocabulário Indo-Europeu (FLORES, 2013, p. 120).

É articulando, então, uma reflexão sobre indivíduo e sociedade a um comentário sobre o texto "Dom e troca" que pretendemos tecer as reflexões que seguem. Para realizar essa reflexão, é importante resgatar alguns trabalhos que a antecedem. Ono (2008) estuda a relação entre a noção de instituição e a de enunciação; Silva e Malcorra (2016) realiza um estudo sobre o texto "Cidades, comunidades" e propõe uma Teoria Social da Enunciação; Silva (2017) faz um estudo sobre a noção de gesto e sua relação com a noção de língua; por fim, Mascarelo e Silva (2017) fazem uma leitura comparada de aspectos da teoria de Mauss e alguns aspectos da teoria da enunciação, a partir da discussão de "Dom e troca".

Uma das primeiras afirmações que devemos fazer é a de que a própria noção de 'dom e troca', cuja relevância para entender fatos sociais foi feita pela primeira vez pelo antropólogo Marcel Mauss, é muito mais do que uma noção sociológica. É uma noção que interessa à linguística. Tal parece ser o propósito do texto "Dom e troca" de Benveniste. A referência ao texto Ensaio sobre a dádiva e sobre seu autor é feita de forma muito pontual em dois pequenos trechos do texto. Para além disso, Benveniste procura demonstrar que essa noção tem consequências para a linguística, uma vez que, a nosso ver, articula o aspecto individual e $o$ aspecto social da linguagem (ONO, 2008).

Antes de analisar o texto "Dom e troca", faremos uma breve retomada de alguns estudos que procuram relacionar $o$ aspecto individual e o aspecto social da enunciação.

Ono (2008) é o único trabalho que encontramos que explora a articulação entre as reflexões do Vocabulário das instituições indo-européias, doravante Vocabulário, e a noção de enunciação contida nos volumes de Problemas de Linguística Geral (PLGs). ${ }^{1}$ Essa articulação é, para este texto importante, pois o tema do 'dom e troca' encontra-se diluído em vários textos do livro Economia do Vocabulário I. Apesar de sua tese estar contida em pouco menos do que duas páginas, ela realiza um belo e produtivo 
ensaio em seu trabalho, que empreende uma análise cronológica do pensamento benvenistiano em busca de noções de enunciação.

Após o estudo do termo enunciação ao longo da história de escrita de Benveniste, Ono (2008) conclui que há três conceitos correlatos ao de enunciação em Benveniste, como três faces de sua evolução, a saber, frase, instância de discurso e enunciado performativo. É justamente nessa última 'face', a instância social, que é possível articular a noção de enunciação dos PLGs e as reflexões sobre sociedade nos Vocabulários. A autora inicia o capítulo "Enonciation et acte de langage" com a seguinte afirmação:

Cette notion ['convention social'] joue un grand rôle dans la théorie d'Austin, et, nous le verrons, elle est également importante pour Benveniste, en particulier dans $\mathrm{VOC}^{2}$ (2008, p. 175).

Para a linguista, o texto "Da subjetividade da linguagem" é o primeiro em que Benveniste trata da performatividade e também é em "A filosofia analítica e a linguagem" que o raciocínio se completa. Se em "Da subjetividade..." está a noção de 'engajamento pessoal'; em "A filosofia analítica e a linguagem" está a noção extralinguística de 'autoridade'. Nesses dois textos, temos uma noção de enunciação como enunciado performativo em sua dimensão social como fazendo parte da dimensão privada.

Entendemos, assim, que as análises contidas nos Vocabulários constituem uma forma de conceituação implícita de enunciação, que ligam a noção de 'autoridade' e a de 'ato de fala' em sua inserção na sociedade, na elaboração teórica de Ono (2008). Para demonstrar esse raciocínio, a autora mostra as análises de Benveniste devotadas às noções de direito, autoridade e juramento no Vocabulário II (BENVENISTE, 1995d), em função de sua ligação evidente com os exemplos contidos no texto "A filosofia analítica e a linguagem" (dos PLGs I) (BENVENISTE, 1989). Acreditamos que esse percurso da autora nos encoraja a traçar uma conceituação teórica mais formulada, mais explícita. Ainda que a autora não tenha problematizado a própria noção de 'instituição', seu raciocínio nos conduz a constituir um paralelo entre os termos enunciação/instituição. Antes de propor uma conceituação mais clara de enunciação a partir dos Vocabulários, vejamos a conclusão de Ono (2008) sobre esse tema.

$\mathrm{Na}$ conclusão de sua reflexão sobre os Vocabulários, a autora apresenta duas "contradições" no pensamento de Benveniste em relação às reflexões de PLGs. Examinaremos essas ditas contradições. A primeira pode ser resumida da seguinte forma:

Tandis que les formules n'interessent pas le Benveniste critique d'Austin, VOC fait la relation entre acte de parole et formules conventionelles issues des institutions sociales (ONO, 2008, p. 194). ${ }^{3}$

Benveniste descreve as sociedades antigas como vendo o Direito como uma 'técnica' e não como uma 'ciên- 
cia', portanto, invenção, em que os locutores repetem 'fórmulas' que lhe são exteriores, e esses enunciados são codificados em Direito. Assim, no Vocabulário, os atos de fala são heterônomos, enquanto em PLGs, são autônomos (ONO, 2008, p. 195). A segunda contradição é a de que ao tratar do juramento, Benveniste traz uma perspectiva fenomenológica (um aspecto 'extralinguístico') para a questão no Vocabulário, que está ausente na discussão do texto de PLGs.

Colocando essas duas ditas contradições em paralelo, observamos que o Vocabulário ora é visto como uma perspectiva de 'fechamento' em torno de ideias linguísticas, ora de 'abertura' a questões de outras ordens - para retomar a distinção proposta por Normand (1996). Essa é uma característica da escrita de Benveniste: cada texto deve ser visto em relação a outros, fato incontornável (FLORES, 2013). Outra questão importante, diferentemente do que afirma Ono (2008, p. 195), a noção de performatividade faz parte, sim, das sociedades antigas e também modernas, no entanto, ela parece ser vista de forma diferente em cada sociedade. Para a sociedade antiga, a performatividade é heterônoma; para a sociedade moderna, ela é mais autônoma - não diríamos autônoma, como para Ono (2008). A distinção entre formas de lidar com a língua e o pensamento em diferentes historicidades está marcada numa distinção que surpreendemos na discussão sobre o par guerra/paz no texto "Cidades, Comunidades" (BENVENISTE, 1995c). Nesse texto, Benveniste ressalta que, nas épocas antigas, toda a designação de caráter étnico se fazia por diferença e oposição, ou seja, em todo o nome que se dá a um povo, há a intenção de distingui-lo dos povos vizinhos, de afirmar uma superioridade linguística. Isso fazia com que as noções de paz e guerra sejam diferentes entre sociedades antigas e modernas, uma vez que, segundo a designação étnica, o estado de guerra é o normal, já para a designação política, o estado de paz é a natural. Como diz Laplantine, leitora com visada heurística de Vocabulário:

[...] lorsqu'on lit le Vocabulaire d'Émile Benveniste, on espérait ensuite que tous les historiens deviennent linguistes, et que tous les linguistes deviennent historiens (2009, p. 125). ${ }^{4}$

Não há contradição entre os PLGs e os Vocabulários, a nosso ver: esse último traz uma visada histórica, para o primeiro, que tem uma visada sincrônica, perspectivas complementares que o par enunciação/instituição ainda deve render muitos debates e conceituações.

Silva e Malcorra (2016) tematizam diretamente a noção de sociedade em Benveniste expressa no Vocabulário e a articula a uma teoria da linguagem. As autoras cunham o termo 'epistemologia para uma teoria social em Benveniste' para dar conta da dimensão social da reflexão do autor. Nesse artigo, Silva e 
Malcorra (2016) informam que o conceito de reciprocidade está atrelado à noção de sociedade em Benveniste e aparece, além do texto de PLGs "Dom e troca", em inúmeros artigos do Vocabulário I, a saber, "Cidades, comunidades", "A hospitalidade" e "O escravo, o estrangeiro". As autoras propõem uma cisão entre os termos 'teoria da enunciação' e 'linguística da enunciação', a partir da cisão entre 'linguística' e 'teoria' proposta por Teixeira (2000). Além disso, analisam as relações terminológicas entre vizinho/ inimigo no texto "Cidades, comunidades" a partir da noção de 'eu' como dupla instância referente e instância referida. Concluem, a partir da análise do texto "Cidades, comunidades", que:

é somente quando o homem se interroga, teoriza sobre sua condição diante do outro - seja esse amigo, inimigo, vizinho, hóspede - é que se torna possível estabelecer trocas linguísticas com esse outro (SILVA; MALCORRA, 2016, p. 251).

Encontramos, nesse texto, indícios, pistas de uma primeira aproximação do conceito de indivíduo com o conceito de pessoa, por meio do conceito de reciprocidade. Assim, a pessoa, como instância referida é tomada pelo outro como um ser com alguma identidade social (amigo, inimigo, vizinho etc.) mas como instância referente pode concordar ou não com essa identidade social. A noção de pessoa redobra, desdobra ou ratifica, reafirma a noção de indivíduo, pela e na linguagem.
Silva (2017), por sua vez, explora a noção de gesto tal como aparece no Vocabulário, no texto "Philos", e em três textos dos PLGs, a saber, "A forma e o sentido na linguagem", "Da subjetividade na linguagem" e "A semiologia da língua". A autora entende a noção de 'gesto' como uma via linguística para compreender as relações entre língua e sociedade. Da análise do texto "Philos", a autora conclui que:

Constatamos que a noção de 'gesto de reciprocidade entre amigos' é fundadora das diversas relações de reciprocidade entre aqueles que se instituem e são instituídos de philia, de amizade. A forma do gesto e a posição em que os sujeitos se encontram e se 'gestualizam' determinam o sentido de tal reciprocidade social, seja de respeito, seja de reverência à igualdade ou à intimidade sexual entre cônjuges. Tal é a produtividade da língua grega, a única em que substantivo e verbo têm a mesma forma (SILVA, 2017, p. 93).

Assim, o gesto é um signo da reciprocidade, portanto, da relação eu-tu. Por fim, a autora conclui seu texto dizendo que o gesto é uma noção linguística de instituição social, elo entre língua e sociedade.

Mascarelo e Silva (2017) buscam estudar a relação entre enunciação e reciprocidade na interação de uma sala de aula de ensino particular de língua inglesa como língua adicional. O referencial teórico se apoia na Enunciação, de Émile Benveniste, em especial o texto "Da subjetividade na linguagem" bem como na noção de reciprocidade, de Mar- 
cel Mauss. Comparando-se formas de reciprocidade descritas por Mauss com conceitos de "dom" e "troca" apresentados por Benveniste, buscam identificar a forma de reciprocidade mais próxima da situação analisada. Durante a análise, as autoras observam que o diálogo entre professor e aluno alterna momentos de "reciprocidade", com grande envolvimento intersubjetivo dos participantes e momentos de "destruição do objeto de discussão', em que o professor retorna à "lesson", isto é, ao livro e à tarefa, voltando-se então para uma rotina de conversa mais burocrática. Apesar de a conclusão mostrar a oscilação da reciprocidade ao longo do diálogo e a relevância disso para as decisões de fala do professor, observamos no trabalho de Mascarelo e Silva (2017) uma analogia muito próxima entre a conceituação de "dom e troca" na obra de Mauss e a noção de 'reciprocidade" em Benveniste, entrevista no texto "Da subjetividade na linguagem", analogia que talvez seja desfeita pelo próprio Benveniste.

Assim, na próxima seção, procuraremos expor um método de leitura de "Dom e troca no vocabulário indo-europeu", considerando as leituras já realizadas sobre língua e sociedade em Benveniste, que podem ser sintetizadas nas seguintes proposições: 1. É possível conceber um conceito enunciativo para a noção de 'instituição' e ver que 'enunciação' e 'instituição' são duas faces do mesmo problema linguístico, qual seja, o problema da língua em ação pelo indivíduo na sociedade; 2 . É possível conceber que pessoa e indivíduo são conceitos correlatos se considerado o conceito de reciprocidade; 3. A noção de gesto, observada em alguns textos do Vocabulário, pode ser concebida como uma categoria de análise enunciativa, da mesma ordem que o são pessoa, tempo e espaço.

\section{Uma leitura de "Dom e troca no vocabulário indo-europeu"}

A primeira orientação de leitura a ser feita é que entendemos que o texto "Dom e troca" deve ser lido como uma reflexão de linguística geral e não como uma reflexão de gramática comparada. Flores (2005) nos conduz a pensar que todo o pensamento de Benveniste é composto de três instâncias entrelaçadas, a saber: a face epistemológica, a face metafísica e a face interdisciplinar. Assim, na face metafísica, acreditamos que Benveniste propõe uma concepção de 'economia enunciativa e linguística' e termos correlatos; na fase interdisciplinar, Benveniste abre a Linguística para receber conceituações da Economia, Sociologia e outras; na face epistemológica, Benveniste nos leva a problematizar pressupostos da própria Linguística ao tomar uma certa posição metafísica e interdisciplinar.

O que essa tomada de posição implica para o campo de estudos da enunciação? Acreditamos que quatro tarefas ao lin- 
guista devem ser postas: 1 . Proposição de uma conceituação teórica; 2 . Problematização de noções anteriores (pressupostos); 3. Elaboração da rede conceitual do autor em torno da noção de dom e troca;

4. Prospecção teórica.

É com base nessas cinco tarefas do linguista que apresentaremos nossa leitura de "Dom e troca no vocabulário indo-europeu".

\section{Proposição de uma conceituação teórica: o conceito de troca}

Logo, no primeiro parágrafo de "Dom e troca", constatamos que Benveniste procura sintetizar a discussão do antropólogo Marcel Mauss e organizá-la em torno da ideia de princípio. Vejamos:

O dom não é apenas um elemento de um sistema de prestações recíprocas ao mesmo tempo livres e obrigatórias, a liberdade do dom obrigando o donatário a um contra-dom, o que gera vaivém contínuo de dons oferecidos e dons compensatórios. Aí está o princípio de uma troca que, generalizada não somente entre indivíduos mas entre os grupos e as classes, provoca circulação de riquezas através da sociedade inteira (BENVENISTE, 1989b, p. 348).

Nessa citação, observamos que a noção de 'dom', proposta pela descrição de Mauss como sistema das sociedades arcaicas, na verdade, redefine-se como 'troca', vinculada a um princípio geral das sociedades. Mais adiante, Benveniste observa que é bem difícil estabelecer para as línguas um 'vocabulário comum' à noção de 'troca'. Vejamos: "Como se pode prever, a 'troca' possibilita um grande vocabulário para especificar as relações econômicas. Os termos dessa ordem, porém, são quase todos renovados, de modo que se deve considerar cada língua por si mesma" (BENVENISTE, 1989b, p. 360).

A conclusão geral que Benveniste toma é de que há sim uma 'origem' econômica, material, diríamos extralinguística, para a ideia de 'dom' ou 'troca'; no entanto, essa origem 'material' é menos importante de sublinhar do que o tipo de sociedade e de relações sociais que se produzem a partir de certos sentidos. Vejamos:

O 'valor' caracteriza-se, na sua expressão antiga, como um 'valor de troca', no sentido mais material. É o valor de troca que possui um corpo humano que se dá por um certo preço. [...]. Por aí se entrevê a origem muito concreta, numa parte do domínio indo-europeu, de uma noção ligada a certas instituições, numa sociedade fundada sobre a escravidão (BENVENISTE, 1989b, p. 360).

\section{Problematização de noções anteriores (pressupostos)}

Benveniste parece desconfiar de uma noção de 'dom' como o 'potlach' descrito por Mauss, isto é, como uma troca exagerada e destrutiva de bens. Vejamos:

Não parece que as sociedades antigas tenham conhecido essa forma exasperada de potlach que muitos escritores, Mauss em particular, descreveram entre os kwakiutl ou os haída, nem esses desafios insensatos nos quais chefes ciosos do seu prestígio se provocam mutuamente a enormes destruições de riquezas (BENVENISTE, 1989b, p. 359). 
Benveniste sublinha que, no mundo indo-europeu, o único traço de sentido de 'potlach' é o de 'alimentação', o de "distribuição de riquezas que chefes distribuem e se beneficiam alternativamente" (1989b, p. 359). Ele enfatiza menos a noção de 'rivalidade' e de 'destruição' e mais a de benefício distribuído alternativamente. Outro aspecto da teoria de Mauss do qual Benveniste parece se distanciar é a relação semântica entre os verbos 'dar' e 'tomar': não há precedência 'histórica' de um sobre o outro. ${ }^{5}$ Não é o 'ato generoso' de 'dar' que engendra o ato de 'tomar'. Vejamos:

A questão parece insolúvel se se procura tirar 'tomar' de 'dar' ou 'dar' de 'tomar'. No entanto o problema está mal proposto. Consideramos que *do- não significa propriamente nem 'tomar' nem 'dar', mas ou um ou outro segundo a construção. [...] só a sintaxe do enunciado o diferenciava em "pegar para guardar (= tomar)" e "pegar para oferecer (=dar)". Cada língua fez prevalecer uma dessas acepções à custa da outra, para constituir expressões antitéticas e distintas de "tomar" e de "dar" (BENVENISTE, 1989b, p. 350).

Podemos concluir que Benveniste afasta-se de dois pressupostos sobre a questão da expressão linguística da noção de 'dom e troca': 1 . A generalidade do par reciprocidade/destruição dos bens para o vocabulário indo-europeu; 2. A antecedência da ideia de 'dar' sobre a ideia de 'receber'. Para o autor, essas ideias nascem juntas (tal como forma e sentido, no texto "A forma e o sentido na linguagem").

\section{Elaboração da rede conceitual do autor}

Primeiramente, apresentaremos dois mapas conceituais que nos ajudarão a compreender as relações conceituais postas no texto "Dom e troca no vocabulário indo-europeu" (BENVENISTE, 1989b). Em seguida, procuraremos relacionar o texto com um conjunto mais amplo de reflexões de Benveniste, de modo a integrar um conceito de enunciação às noções de economia em seu fundamento linguístico.

O mapa apresenta, à direita, a conceituação de "Dom e troca" proposta e, à esquerda, como essa conceituação é expressa nas várias línguas arcaicas citadas por Benveniste. Com esse mapa, esperamos deixar claro que a noção geral de 'prestação recíproca' é entendida ou expressa em cada língua por 'instituições' diferentes, tais como o 'potlach', na língua que não é europeia, e as instituições da 'escravidão', da 'homenagem', da 'hospitalidade' e da 'prestação compensatória', nas línguas indo-europeias. Além disso, uma das conclusões a que esse mapa permite chegar é que a mesma sociedade que tem a relação de 'escravidão' 'é aquela que presta 'homenagem' e que faz 'hospitalidades'. 
Figura 1 - Diversidade das línguas e diversidade de sistemas de prestações recíprocas

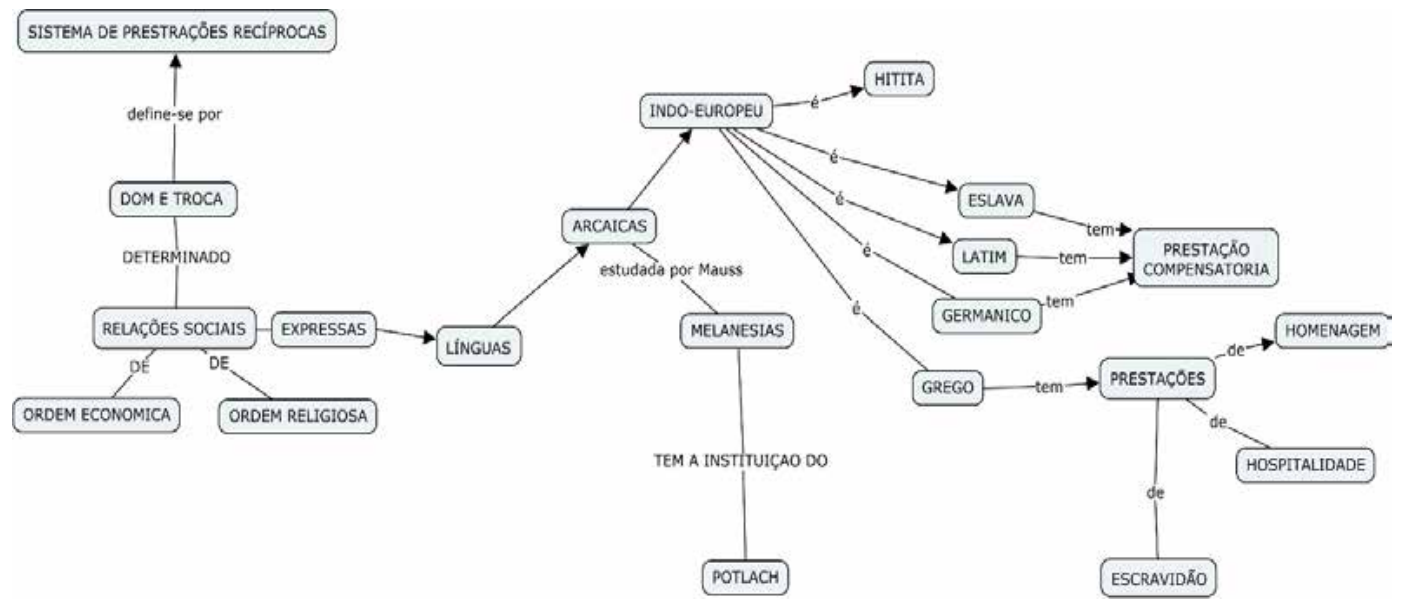

Fonte: elaboração da autora.

Todavia, a Figura 1 não permite entrever as relações de reciprocidade entre as sociedades indo-iranianas e as sociedades indo-europeias, isto é, as semelhanças e cisões dentro do vocabulário indo-europeu. É o que tentaremos fazer com a Figura 2, a partir da discussão de Benveniste sobre o termo latino munus. "Poder-se-ia retraçar, com a ajuda e ao redor de múnus, toda uma fenomenologia indo-européia da 'troca”' (BENVENISTE, 1989b, p. 356). Como veremos, na Figura 2, o próprio léxico de comunidade depende dessa discussão.
Figura 2 - Cisão no vocabulário indo-europeu e nascimento da noção de comunidade

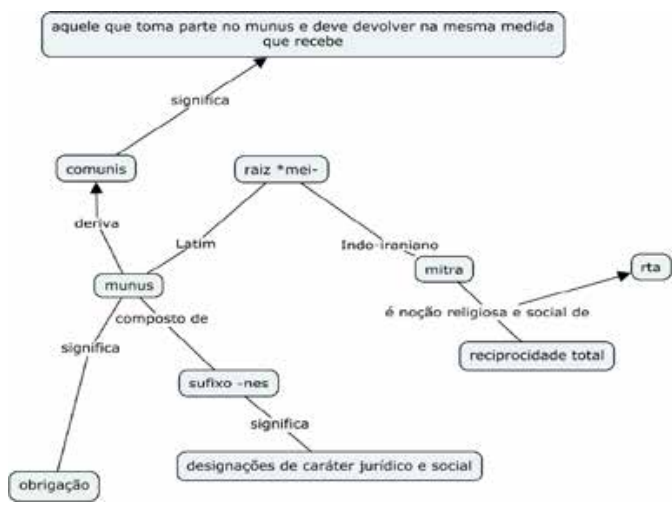

Fonte: elaboração da autora.

Como podemos observar, nas línguas indo-iranianas não houve processo morfológico de derivação; diferentemente das língua latinas. Assim, nas sociedades indo-iranianas, a noção de 'troca, obri- 
gação' está vinculada à ideia de reciprocidade total, do tipo religioso-social (e talvez mais próxima do potlach de que fala Mauss) e nas sociedades latinas essa noção especializou-se em diversas noções, ora jurídico-sociais, ora religiosas; temos, portanto, tipos de reciprocidade. Essa cisão cultural entre o indo-iraniano e o indo-europeu é entrevista também por Silva e Malcorra (2016), para as noções de 'guerra' e 'paz' no texto "Cidades, comunidades" (de Vocabulário I), e revela que a noção de 'dom e troca' desenvolveu sentidos completamente diferentes nas duas culturas.

Para poder aproximar as definições do texto "Dom e troca" com um conjunto mais amplo de reflexões de Benveniste, procuramos relacionar a definição de dom e troca do texto "Dom e troca no vocabulário indo-europeu", ao texto "Dar, tomar, receber", do Vocabulário I, e ao texto "Da subjetividade na linguagem", isto é, demonstrar a tese de que enunciar é um gesto para estabelecer uma relação de prestações recíprocas com o parceiro, sejam essas relações da ordem da submissão do outro, da sua edificação, da simples troca de bens, da hospitalidade ou da compensação. Lembramos que a tese de que enunciar é um gesto está presente na argumentação de Silva (2017).

Façamos antes uma leitura preparatória do texto "Dar, tomar e receber" (BENVENISTE, 1995a), de onde retiramos a ideia de 'gesto' como constituinte do sentido primitivo de 'tomar' em latim; em seguida, uma leitura de "Da subjetividade na linguagem" (BENVENISTE, 1989a), de onde retiramos a ideia da relação de reciprocidade entre eu-tu. As noções de 'submissão', 'edificação', 'troca', 'hospitalidade' e 'compensação' foram retiradas da leitura do texto "Dom e troca no vocabulário indo-europeu" (BENVENISTE, 1989b).

Benveniste afirma que "os termos de compra e venda não se separam dos de 'dar' e tomar" (1995a, p. 79, grifo nosso). Após demonstrar que o termo 'tomar' tem história diferente para o latim e o para o germânico, Benveniste conclui o texto dizendo que:

A maneira como emo [comprar] se especifica em latim parece confirmar que o sentido de "comprar" implica uma representação totalmente diversa dos termos do gr. pernemi etc. É claro que emo quer dizer primeiramente "tomar para si, puxar para si"; a posse afirmada dessa maneira se exprime pelo gesto do homem que pega e puxa o objeto para si. O sentido de "comprar" deve ter se aplicado inicialmente a seres humanos, tomados após se fixar um preço. A noção de compra tem sua origem no gesto que conclui a compra (emo) e não no fato de pagar um preço, quitar um valor (BENVENISTE, 1995a, p. 83-84, grifo nosso).

Embora Benveniste esteja se referindo à formação do termo em latim, fica implícito que a noção de gesto está na base do sentido do termo para o germânico também, a saber, "gesto que acolhe, recebe" (1995a, p. 84).

Em "Da subjetividade na linguagem", flagramos o termo 'reciprocidade'.Vejamos: 
A consciência de si mesmo só é possível se experimentada por contraste. Eu não emprego eu a não ser dirigindo-me a alguém, que será na minha alocução um tu. Essa condição de diálogo é que é constitutiva da pessoa, pois implica em reciprocidade - que $e u$ me torne $t u$ na alocução daquele que por sua vez se designa por eu (BENVENISTE, 1989a, p. 286).

Falta um elemento nessa relação entre gesto e troca: o objeto da troca. Em "Dom e troca no vocabulário indo-europeu", Benveniste (1989b) mostra que o objeto de troca é o próprio sujeito nas sociedades de prestação total e um "escravo" na sociedade grega (indo-europeu). Há uma diferença linguística importante. Já em "Da subjetividade na linguagem”, o 'objeto' é a 'língua apropriada' (1989a, p. 288).

Para utilizar uma metáfora de Ono (2008), com esses três textos temos a face do conceito 'social' de enunciação em Benveniste completada: as noções correlatas de 'prestações recíprocas', 'gesto' e ‘objeto apropriado' constituem, a nosso ver, os elementos básicos para se esboçar o 'rosto' de um conceito de enunciação que está na fronteira entre linguística e sociologia.

\section{Prospecção teórica}

O texto "Dar, tomar e receber" (BENVENISTE, 1995a) faz parte do Livro 1 do Volume I do Vocabulário das instituições indo-européias. Este livro é dividido em quatro seções, a saber, A economia, Dar e tomar, A compra e As obrigações econômicas, totalizando dezessete capí- tulos. Interessante observar que o tema da 'reciprocidade' reaparece com força no último capítulo da quarta seção, a saber, Gratitude e reconhecimento. Nesse capítulo, Benveniste analisa o termo latino gratia e conclui que:

Tal é o ponto de inserção de um termo de sentimento nos valores econômicos, sem contudo, que haja uma ruptura com as representações religiosas que lhe serviram de berço (1995b, p. 200).

Vemos aí o enlace da instituição 'economia' com a instituição da 'religião', mediante um termo que surge em uma determinada língua.

A noção de reciprocidade tem uma 'nova' modalidade:

Mas o ir-e-vir da prestação e do pagamento pode ser interrompido voluntariamente: serviço sem retorno, oferta por favor, pura "graça", abrindo uma nova reciprocidade. Acima do circuito normal das trocas, daquilo que se dá para se receber, existe $u m$ segundo circuito, o da beneficência e do reconhecimento, daquilo que é dado sem espírito de retorno, daquilo que é ofertado para 'agradecer' (BENVENISTE, 1995b, p. 200, grifo nosso).

A definição de enunciação exposta ganha então o retrato final, (ao menos nas línguas que herdaram as concepções culturais do latim), a saber, enunciar é também um gesto que transcende a troca, sendo pura oferta, ato de reconhecer o outro em sua possibilidade de troca, de diálogo. A tautologia aqui é proposital: é Ego que diz ego.

Seria a 'gratitude' o outro lado da 'reciprocidade'? Suplemento, um além de...? Benveniste, na citação transcrita, 
diz que é um 'segundo circuito'. A questão que fica é a seguinte: todo ato enunciativo teria, então, dois circuitos, dois níveis de reciprocidade? Evidentemente, essa é uma questão teórica que talvez só o estudo da relação entre a comunhão fática - essa forma de reciprocidade sem conteúdo - e a definição clássica de enunciação pode elucidar.

\section{Desafios para a proposição de uma Teoria Social da Enunciação}

Pensar uma Teoria Social da Enunciação significa pensar o estatuto e as relações que a Linguística e a Sociologia estabelecem hoje. Não vemos sociólogos citarem frequentemente linguistas ${ }^{6}$; vemos a linguística se aproximando de explicações sociais e própria Sociolinguística criticando e revendo seus próprios procedimentos (LUCCHESI, $2015^{7}$ ).

Entendemos que noções advindas da Sociologia (tais como 'dom e troca') bem como de outras áreas da Ciências Humanas, tais como a noção de 'falta de objeto' na Psicanálise (Lacan, $\mathrm{O}$ seminário, livro 4, A relação de objeto) devem constituir um horizonte teórico para os estudos enunciativos. Assim, tal como propõe Dufour (2000), a Sociologia e a Psicanálise poderiam constituir uma exterioridade teórica à linguística. Como lembra Flores (2005), Benveniste tem uma face interdisciplinar, que, acreditamos, ainda resta muito a discutir. Sabemos ainda da necessidade de articular tais conceitos e definições a uma teoria da linguagem: ${ }^{8}$ como se concebem língua, linguagem e línguas nessa perspectiva? Como se analisa os fatos enunciativos? Que problemas de linguagem o linguista pode dar conta? Como propor uma definição linguística para a noção de 'reciprocidade'?

Uma tarefa, bem mais ambiciosa certamente, seria procurar integrar os princípios enunciativos a todas as instituições propostas por Benveniste no 'monumental' Vocabulário. Silva e Malcorra (2016) exploraram somente um artigo do livro Estatutos Sociais.

O que este texto tentou explanar e defender é que enunciar é também 'trocar': as palavras carregam 'objetos de fala' que são transacionados nas relações sociais que os locutores estabelecem, sejam estas quais forem. Parece-nos que Derrida tem uma ótima intuição sobre o tema ao escrever, tal como citado na epígrafe: "a mão do homem dá e se dá, guarda ou retira, é dom que faz e dom que faz mal, presente e veneno" (2016, p. 512). 


\section{Gift and exchange in the Indo- european vocabulary: an essay on a text by Émile Benveniste}

\begin{abstract}
The presente article intends to make a commentary on the text "Dom e troca no vocabulário indo-europeu", looking for to observe its relations with texts of the section "O homem na língua", of Problemas de Linguística Geral, and also with discussions present in the book Economy, of Vocabulário das instituições indo-européias. This commentary will cover four tasks: 1. proposing a theoretical conceptualization; 2. Problematizing previous notions (presuppositions); 3. proposing a re-elaboration of the conceptual network of the author; 4 . raising hypotheses for a theoretical prospect.
\end{abstract}

Keywords: Émile Benveniste. Give and take. Reciprocity. Enunciation theory.

\section{Notas}

1 Os trabalhos de Lamberterie (1997) e de D'Ottavi (2014) debruçam-se sobre o Vocabulário. Voltam-se, a nosso ver, para um Benveniste comparatista, gramático das línguas.

2 "Essa noção ['convenção social'] desempenha um papel na teoria de Austin, e, como veremos, ela é igualmente importante para Benveniste, em particular no VOC" (2008, p. 175, tradução nossa).

3 "Embora as fórmulas não interessem ao Benveniste crítico de Austin, o VOC faz a relação entre o ato de fala e fórmulas convencionais provenientes de instituições sociais" (tradução nossa).

4 "Quando lemos o Vocabulário de Émile Benveniste, esperamos que todos os historiadores se tornem linguistas e que todos os linguistas se tornem historiadores" (tradução nossa).
5 É interessante observar que Mauss (2015), em Ensaio sobre a dádiva, mesmo não fazendo qualquer referência a estudos do campo da Linguística, utiliza-se de diversos procedimentos linguísticos para analisar as sociedades arcaicas. São eles: 1) distinção entre noção e termo; 2) definição de diversos termos linguísticos a partir das problemáticas antropológicas; 3 ) discussão de traduções de termos feitos por outros antropólogos.

6 Em uma breve pesquisa sobre os estudos sobre 'dom e troca' entre sociólogos, observamos que Bourdieu (1996) é um dos poucos que cita o trabalho de Benveniste. Para o autor, Benveniste analisa o indo-europeu como uma 'revolução' da noção de economia do tipo 'dom e troca'. Vejamos: "Aeconomia do 'toma lá, dá cá' é o produto de uma revolução simbólica que, nas sociedades européias, se realizou progressivamente, com, por exemplo, todos os processos insensíveis de desvelamento e de 'desambiguização', dos quais o Vocabulário das instituições indo-européias, analisado por Benveniste, conserva vestígios, e que levaram do resgate - do prisioneiro - à aquisição, do prêmio - por um feito relevante - ao salário, do reconhecimento moral ao reconhecimento de dívida, da crença ao crédito, da obrigação moral à obrigação jurídica diante de um tribunal" (1996, p. 11, grifos nossos). A nosso ver, parece que Bourdieu não leu com a devida atenção o texto "Gratuidade e reconhecimento" (1995b), já referido, uma vez que reduz a dimensão da discussão de Benveniste a surgimento da economia do 'toma lá, dá cá' e ao problema do capitalismo nas sociedades modernas.

7 Uma das grandes discussões de Lucchesi (2015, p. 71) é mostrar a insuficiência do conceito de 'comunidade de fala' para dar conta das mudanças linguísticas em determinadas comunidades linguísticas; o autor propõe, com base em Milroy e Milroy, a noção de rede social. Indivíduos que circulam em mais de uma comunidade de fala tem maior poder de mudança linguística nas comunidades do que indivíduos que têm laços fortes com uma única comunidade de fala.

8 Agradeço a interlocução instigante e as questões de Gabriela Barboza (Doutoranda-PPGLET-Ufrgs) durante a apresentação deste texto no II Colóquio Leituras de Émile Benveniste, Passo Fundo, Universidade de Passo Fundo, 10 de agosto de 2018. 


\section{Referências}

BENVENISTE, E. Da subjetividade na linguagem. In: . Problemas de linguística geral I. Campinas, SP: Pontes, 1989a. p. 284-293.

A filosofia analítica e a linguagem. In: . Problemas de Linguística Geral I. Campinas, SP: Pontes, 1989. p. 294-305.

Dom e troca no vocabulário indo-europeu. In: . Problemas de linguística geral I. Campinas, SP: Pontes, 1989b. p. 348-360.

Dar, tomar e receber. In:

Vocabulário das instituições indo-européias. Volume I. Campinas, SP: Pontes, 1995a, p. 79-84.

Gratitude e reconhecimento. In: Vocabulário das instituições indo-européias. Volume I. Campinas, SP: Pontes, 1995b. p. 197-200.

. Cidades, comunidades. In: Vocabulário das instituições indo-européias. Volume I. Campinas, SP: Pontes, 1995c. p. 357-367.

. Vocabulário das instituições indo-européias. Volume II. Campinas, SP: Pontes, $1995 \mathrm{~d}$.

BOURDIEU, Pierre. Marginalia. Algumas notas adicionais sobre o Dom. Mana, Rio de Janeiro, v. 2, n. 2, p. 7-20, 1996.

DERRIDA, Jacques. La mano del Heidegger. In:__. Psyché. Invenciones del otro. Adrogué: Ediciones La Cebra, 2016. p. 495-534.

D'OTTAVI, Giuseppe. Designer et signifier le "savoir": pour une nouvelle entrée du Vocabulaire des instituitions indo-européennes d'Emile Benveniste. Congrès Mondial de Linguistique Française. 2014.

DUFOUR, Dany Robert. Os mistérios da trindade. Rio de Janeiro: Companhia de Freud, 2000.
FLORES, Valdir do Nascimento. Introdução à teoria enunciativa de Benveniste. São Paulo: Parábola, 2013.

Por que gosto de Benveniste? Desenredo, Passo Fundo, v. 1, n. 2, p. 127-138, jul./ dez. 2005.

ONO, Aya. La notion d'énonciation chez Benveniste. Limoges: Lambert-Lucas, 2008.

NORMAND, Claudine. Os termos da enunciação em Benveniste. In: OLIVEIRA, S.; PALATO, E.; RABELLO, S. O falar da linguagem. São Paulo: Lovise, 1996. p. 129-151.

LAMBERTERIE, Charles de. A propos du vocabulaire des institutions indo-européennes. In: NORMAND, Claudine (Org.). Emile Benveniste vingt ans après. Actes du Colloque de Cerisy. Paris X, 1997. p. 355-364.

LAPLANTINE, Chloé. Emile Benveniste et Le Vocabulaire des institutions indo-européennes. In: JOUBERT, Claire (Dir.). Le texte étranger (2), Travaux 2006-2008. SaintDenis: Presses universitaires de Vincennes, 2009. (Collection « Travaux et documents »). p. $125-130$.

LUCCHESI, Dante. Fundamentos teóricos. In: _. Língua e sociedade partidas: a polarização sociolinguística do Brasil. São Paulo: Contexto, 2015. p. 45-122.

MAUSS, Marcel. Ensaio sobre a dádiva. Tradução de Paulo Neves. São Paulo: Cosac Naify, 2015.

SILVA, Silvana. Uma leitura das relações entre língua e sociedade em Émile Benveniste a partir da noção de gesto. Desenredo, Passo Fundo, v. 13, n. 1, p. 88-99, jan./abr. 2017.

SILVA, Silvana; MALCORRA, Barbara. Sociedade, sociedades: epistemologia para estabelecer princípios de uma Teoria Social da Enunciação. Contexto(s) Linguístico(s), Vitória, v. 10, n. 17, p. 236-253, 2016.

MASCARELO, Mégui; SILVA, Silvana. Reciprocidade e enunciação na cultura de interação em uma classe de língua inglesa em Bagé. Guavira Letras, Três Lagoas, MS, n. 25, p. 139-151, jul./dez. 2017. 